\title{
LA PERFECCIÓN DE ALGUNOS ENDECASÍLABOS «IMPERFECTOS» DE GARCILASO DE LA VEGA
}

\author{
THE PERFECTION OF CERTAIN 'IMPERFECT' \\ HENDECASYLLABLES IN GARCILASO DE LA VEGA
}

\author{
ESTEBAN TORRE \\ Universidad de Sevilla
}

\begin{abstract}
Resumen: Un exhaustivo análisis de la totalidad de los versos endecasílabos de Garcilaso de la Vega descarta la existencia en ellos de cualquier clase de imperfección o irregularidad. Asimismo, se pone de manifiesto en este trabajo la ausencia absoluta de endecasílabos dactílicos en la obra del poeta toledano, contrariamente a lo que en general ha venido siendo sostenido por la crítica erudita.
\end{abstract}

Palabras clave: Garcilaso de la Vega, endecasílabos dactílicos, endecasílabos imperfectos, endecasílabos irregulares.

\begin{abstract}
A thorough analysis of the total corpus of Garcilaso de la Vega's hendecasyllabic lines rules out the occurrence within it of any kind of imperfection or irregularity. In that same sense, this discussion brings to the fore the absence of dactylic hendecasyllables in the Toledo-born poet's output, contrary to what, generally speaking, specialist critics have always maintained.
\end{abstract}

Key words: Garcilaso de la Vega, dactylic hendecasyllables, imperfect hendecasyllables, irregular hendecasyllables. 

T a perfección del verso endecasílabo de Garcilaso de la Vega -introductor, junto con Juan Boscán, de esta forma métrica en la poesía castellana, y punto de arranque de la moderna literatura española- no impide que algunos críticos y teóricos hayan querido señalar en su obra la existencia de versos irregulares o defectuosos, que no se atienen a las pautas generalmente admitidas como canónicas para el endecasílabo español. Se aducen, así, casos de endecasílabos dactílicos ${ }^{1}$ y de acentuación anómala o deficiente. A continuación, se tendrán en cuenta las distintas circunstancias en las que el verso garcilasiano haya podido dar motivo, de alguna forma, a tales calificaciones.

Los versos que más frecuentemente se presentan como ejemplos de endecasílabos dactílicos son los siguientes²:

$$
\begin{array}{ll}
\text { Tus claros ojos ¿a quién los volviste? } & \text { (Égloga I, 128) } \\
\text { En esto 'stoy y estaré siempre puesto } & \text { (Soneto V, 5) }
\end{array}
$$

En relación con el primero de estos dos supuestos endecasílabos dactílicos, Elias L. Rivers advierte en su edición de las

${ }^{1}$ El endecasílabo dactílico, cuyo ritmo ternario podría asimilarse al del dodecasílabo castellano medieval, no tuvo buena acogida en la nueva métrica italianizante del Renacimiento, a pesar de haber sido empleado profusamente en la lengua toscana por el maestro Petrarca. Caso distinto habría de ser el de las cláusulas trisilábicas de la poesía romántica y, sobre todo, de la poesía modernista, en donde se inserta muy bien el ritmo ternario del endecasílabo dactílico. Aparece, así, en composiciones de Rubén Darío, Salvador Rueda, Francisco Villaespesa y algunos poetas menores. Su eco llega hasta Gerardo Diego, Rafael Alberti o Miguel Hernández. No se encuentra en Juan Ramón Jiménez, ni en Manuel Machado, ni en Antonio Machado. Vid. un amplio y documentado estudio sobre esta forma métrica en Domínguez Caparrós, José: El moderno endecasílabo dactílico, anapéstico o de gaita gallega. Anejo III de Rhythmica. Revista Española de Métrica Comparada. Sevilla: 2009.

${ }^{2}$ Si no se advierte otra cosa, todas las citas se harán por Garcilaso de la Vega: Obras completas con comentario, edición crítica de Elias L. Rivers. Madrid: Castalia, 1981. 
Obras completas de Garcilaso que ya Tomás Navarro Tomás había llamado la atención sobre «el carácter dactílico de este verso, que lleva acento en la $7^{\mathrm{a}}$ sílaba (cfr. Henríquez Ureña, $R F E$, VI, [1919], 132-157)» ${ }^{3}$. A este respecto, Miguel Ángel Márquez ${ }^{4}$ precisa que «de hecho, en toda la obra de Garcilaso, sólo se aducen unos pocos casos que dudosamente pueden ser considerados endecasílabos dactílicos» $»^{5}$ y añade en nota:

E. Torre postula que esos escasos ejemplos de dactílicos en Garcilaso de la Vega podrían resolverse si tenemos en cuenta las diferencias que separan el castellano de Garcilaso de la Vega de nuestro español culto. En el caso de Égloga I, 128, podría considerarse la posibilidad de que el pronombre «los» fuera tónico; así el verso cumpliría función rítmica. En el caso de Soneto V, 5, la solución habría que buscarla en la forma verbal «estaré», cuyo origen perifrástico es «estar he». La acentuación aguda del infinitivo de la perífrasis («estár») daría como resultado un verso con acentos en $2^{\mathrm{a}}, 4^{\mathrm{a}}, 6^{\mathrm{a}}, 8^{\mathrm{o}}$ y $10^{\mathrm{a}}$ sílabas $^{6}$.

En efecto, los dos versos citados se adaptan perfectamente a las formas canónicas del endecasílabo; el primero como endecasílabo sáfico, y el segundo como pentámetro yámbico:

tus.clá.ros.ó.jos.a.quien.lós.vol.vís.te en.és.to’s.tóy.yes.tá.re.siém.pre.pués.to

En el primero de estos dos versos (Égloga I, 128), el pronombre «los» refuerza con el acento de intensidad el movimiento de los ojos de la mujer amada, que rehúyen la mirada del poeta. Por lo demás, la acentuación de las formas pronominales, generalmente átonas, no es excepcional en poemas del siglo XVI, y tampoco lo es en composiciones contemporáneas, incluso en posición enclítica, según puede apreciarse en los siguientes endecasílabos de Blas de Otero:

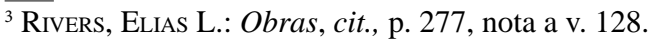

${ }^{4}$ El profesor Márquez es autor de un enjundioso artículo sobre la tipología del endecasílabo, basada en su ritmo acentual, que se define en términos de cláusulas cuaternarias y binarias. Vid. Márquez, Miguel Ángel: «Ritmo y tipología del endecasílabo garcilasiano». RLit, 2009, LXXI, 141, pp. 11-38. Este artículo ha servido de estímulo y punto de partida para la elaboración del presente trabajo.

${ }^{5}$ Ibid., p. 20.

${ }^{6}$ Ibid., nota 22.
} 


$$
\begin{aligned}
& \text { de encima. Déjame, con mi vacío }{ }^{7} \\
& \text { deen.cí.ma.dé.ja.mé.con.mi.va.cí.o } \\
& \text { O si no, déjanos precipitarnos } \\
& \text { o.si.nó.de.ja.nós.pre.ci.pi.tár.nos }
\end{aligned}
$$

En el segundo verso (Soneto V, 5), hemos de tener presentes la formación y la historia del futuro en lengua romance. Como es sabido, se realiza mediante el compuesto de infinitivo + presente: estar he > estaré. Como ya hizo ver don Ramón Menéndez Pidal, «la lengua no perdió el sentido de la composición de estos tiempos sino muy entrada la Edad Moderna» ${ }^{9}$. Por esta razón, se admitía la interposición de uno o más pronombres entre el infinitivo y el auxiliar: dar le has, por le darás; traer nos lo has, por nos lo traerás.

Es obvio que, como palabras aisladas, tanto «quién» como «estaré» son portadoras de acento, en contigüidad a «los» en el primer verso, y a «siempre» en el segundo. Ahora bien, como ya el metrista gaditano Eduardo Benot había hecho notar a finales del siglo xix, en el verso endecasílabo «no deben concurrir inmediatas i tocándose dos sílabas intensas i vigorosas», ya que el acento natural constituyente hace que el acento contiguo «se ofusque i desvanezca» ${ }^{10}$.

Ocurre que el acento, por sí mismo, no es en el verso español una entidad absoluta, sino relativa: la sílaba acentuada lo es siempre en relación a un entorno, esto es, a la sílaba que la precede y a la sílaba que la sigue. En realidad, todas las sílabas, en sí mismas, son tónicas: todas llevan acento, todas gozan de una intensidad acústica o energía suficiente para que puedan ser perceptibles; todas tienen un determinado tono o frecuencia de ciclos sonoros. Pero llamamos tónica a la sílaba más acentuada en relación a un entorno de sílabas menos acentuadas, que tienen la consideración de átonas.

Las sílabas átonas, contiguas a la tónica en la secuencia versal, pueden ser portadoras de acento en las palabras aisladas a

${ }^{7}$ OTERo, Blas de: «Lastima», en Ancia. Madrid: Visor, 1971, p. 49, v. 2.

${ }^{8}$ Otero, Blas de: «Basta», ibid., p. 40, v. 13.

${ }^{9}$ MenÉndez Pidal, Ramón: Manual de gramática histórica española, 14 a . ed. Madrid: Espasa-Calpe, 1973, p. 324.

${ }^{10}$ Benot, Eduardo: Prosodia castellana i versificación [1892], edición facsímil al cuidado de Esteban Torre. Sevilla: Padilla Libros, 2003, I, p. 198. 
las que pertenecen. En estas circunstancias, reciben a veces la denominación de sílabas con acento antirrítmico. Señala Miguel Ángel Márquez que estos acentos antirrítmicos, «situados en posición inmediata a un acento rítmico, implican una elevación del tono» ${ }^{11}$, y anota:

Según Torre, en los casos en los que concurren dos acentos contiguos, teniendo en cuenta que el tono de cada sílaba depende del entorno, una de las dos sílabas sería más relevante por el tono y asumiría la función rítmica del verso ${ }^{12}$.

Convendría precisar que el acento rítmico está en función no sólo del tono o frecuencia de cada una de las sílabas, sino también y fundamentalmente de la energía o intensidad acústica de ellas. En ocasiones, el tono viene a matizar el ritmo y a resolver el posible conflicto entre el papel del acento de intensidad en la palabra aislada y su posición en el conjunto de la secuencia versal. Es lo que ocurre, por ejemplo, en el verso «cierra la puerta, hijo mío» de Federico García Lorca ${ }^{13}$. Como palabra aislada, «hijo» es portadora de acento en su primera sílaba. Sin embargo, en la línea del verso (cié.rra.la.puér.tahi.jo.mí.o), la mayor energía del acento de intensidad que incide sobre la primera sílaba de la palabra «puerta» hace que la sílaba hi- (de hijo) quede absorbida por zeuxis o sinalefa en la sílaba átona -ta (de puerta), de manera que la sílaba resultante -tahi- es átona en la secuencia versal. Pero ocurre, no obstante, que la palabra «hijo» conserva una cierta independencia acentual con respecto a la palabra "puerta», en virtud del tono o frecuencia acústica. Existe, en efecto, entre puér- y -tahi- un sensible cambio de tono, lo cual no tiene que implicar necesariamente una elevación del mismo. En el caso que nos ocupa, se aprecia entre puér- y -tahi- un semitono descendente. En otros términos: puér-es el sostenido de -tahi-, o -tahi- es el bemol de puér-.

Aduce Márquez otros dos posibles ejemplos de endecasílabo dactílico en Garcilaso de la Vega:

${ }^{11}$ MÁRquez, Miguel Ángel: «Ritmo», cit., p. 14.

${ }^{12}$ Ibid., p. 15, nota 10.

${ }^{13}$ Vid. Torre, Esteban: El ritmo del verso (Estudios sobre el cómputo silábico y la distribución acentual, a la luz de la Métrica Comparada, en el verso español moderno). Murcia: Universidad, 1999, pp. 42-50. 
Está y estará tanto en mí clavada hinchen el aire de dulce armonía

(Égloga III, 7)

(Égloga II, 69)

En el primero de estos dos endecasílabos, análogamente a lo que ocurre en Soneto V, 5, habría que leer el verbo estará como estar ha, con lo que estaríamos en presencia de un pentámetro yámbico:

es.tár.yes.tár.ha.tán.toen.mí.cla.vá.da

Pero, al parecer, no podríamos hacer con la misma facilidad una lectura regular del segundo verso, «cuyo ritmo dactílico -se afirma- es incuestionable» ${ }^{14}$. Habría que precisar, sin embargo, que entre el verbo «hinchen» y la partícula «de» existe una fuerte rección o relación gramatical. La partícula «de» no es aquí meramente una preposición (pre-posición) átona, antepuesta (ante-puesta) al sintagma nominal «dulce armonía», sino que está estrechamente ligada al verbo «hinchen», cuyo significado completa y especifica, adquiriendo así un marcado relieve semántico y fonético en la línea del verso.

Por otra parte, las similitudes y los contrastes de timbre que se dan entre las sílabas de/dul-, ambas con dental inicial, resalta aún más la privilegiada posición $6^{\mathrm{a}}$ de la sílaba de, que se equilibra en suave balanceo con la sílaba $7^{\mathrm{a}} d u l$ - (de dulce). Tras el fuerte impulso de la sílaba $4^{\text {a }}$ (áy-, de ayre), se suceden «con dulce armonía» los tonos y las intensidades de las restantes sílabas, hasta llegar a la $10^{\mathrm{a}}$ sílaba final. Es algo análogo en lo que ocurre en el siguiente endecasílabo:

A propósito de este verso, Fernando de Herrera nos advierte que «à de leerse haziendo assiento en el árbol» ${ }^{15}$. Es tan fuerte, en efecto, el acento de la sílaba $4^{a}$ (ár-, de árbol) que todas las demás quedan debilitadas hasta llegar a la $10^{\mathrm{a}}$ final. Así pues,

${ }^{14}$ Márquez, Miguel Ángel: «Ritmo», cit., p. 20, nota 22.

${ }^{15}$ Herrera, Fernando de: Obras de Garcilaso de la Vega con anotaciones [1580], edición facsimilar de Antonio Gallego Morell. Madrid: CSIC, 1973, p. 191, nota a cortaste. 
tanto en Égloga II, 69, como en Soneto XXV, 3, podemos hacer la siguiente lectura:

hin.chen.el.áy.re.de.dul.cear.mo.ní.a

cor.tas.te’l.ár.bol.con.ma.nos.da.ñó.sas

Otros endecasílabos podemos encontrar, en la obra poética de Garcilaso de la Vega, con fuerte acentuación en las sílabas $4^{\text {a }}$ y $10^{\mathrm{a}}$, y con intensidades y tonos más atenuados en las sílabas intermedias. Este tipo de endecasílabo ha sido tildado a veces de verso «desmayado», aunque también puede considerarse como una variedad del endecasílabo sáfico:

$\begin{array}{ll}\text { pienso remedios en mi fantasía } & \text { (Soneto III, 6) } \\ \text { libre el lugar a la desconfíanza } & \text { (Soneto IV, 4) } \\ \text { en salvo destos acontecimientos } & \text { (Soneto XX, 6) } \\ \text { Después acá de lo que consentí } & \text { (Soneto Soneto XXVII, 5) } \\ \text { A romper esto en que yo me metí } & \text { (Soneto XXVII, 8) } \\ \text { mas es a tiempo que de mi bajeza } & \text { (Soneto XXVIII, 7) } \\ \text { un dulze amor, y de mi sentimiento } & \text { (Soneto XXXI, 2) } \\ \text { me quexo a vos como si en la verdad } & \text { (Canción II, 24) } \\ \text { un campo lleno de desconfianza } & \text { (Canción IV, 89) } \\ \text { Algunos premios o agradecimientos } & \text { (Elegía I, 92) } \\ \text { se contradicen en lo que profieren } & \text { (Elegía II, 15) } \\ \text { Quál es el cuello que como en cadena } & \text { (Égloga I, 131) } \\ \text { Al sueño ayudan con su movimiento } & \text { (Égloga II, 76) } \\ \text { Tras esto luego se me presentaba } & \text { (Égloga II, 1122) } \\ \text { Salir el humo de las caserías } & \text { (Égloga II, 1871) }\end{array}$

Todos estos versos han de leerse poniendo énfasis -haziendo assiento, según el sentir de Herrera- en la palabra portadora del acento correspondiente a la sílaba $4^{\mathrm{a}}$. No se trata en absoluto de versos defectuosos, flojos o desmayados, sino que, por el contrario, las dos cúspides acentuales de las sílabas $4^{\mathrm{a}}$ y $10^{\mathrm{a}}$, en contraste con la suave atenuación rítmica de las restantes sílabas, cumplen un oportuno papel de moderación y contrapunto en la serie versal. Más que de descuido o defecto, habría que hablar de exquisita labor de cincelado poético.

En algunos otros endecasílabos de Garcilaso de la Vega, podría llevarse a cabo una doble lectura: como endecasílabos dactílicos con acento en la sílaba $7^{\mathrm{a}}$, o como endecasílabos canónicos. 
En todos estos casos, es fácil llevar a cabo una adecuada lectura, desplazando el hipotético acento de la sílaba $7^{\mathrm{a}}$ a la sílaba inmediatamente anterior $\left(6^{\mathrm{a}}\right)$ o posterior $\left(8^{\mathrm{a}}\right)$ :

y a ver los passos por do m'han traído ya-vér-los.pá.sos.por.do.m’hán.tra.í.do

(Soneto I, 2)

hallo, según por do anduve perdido há-llo.se.gún.por.dóan.du.ve.per.dí.do

(Soneto I, 3)

sé que me acabo, y más é yo sentido

sé.que.mea.cá.boy.más.e.yó.sen.tí.do

(Soneto I, 7)

como remedio más ya deffendido

co.mo.re.mé.dio.más.ya.def.fen.dí.do

(Soneto II, 4)

mi inclinación por quien ya no porfío

miin.cli.na.ción.por.quién.ya.no.por.fí.o

(Soneto VI, 12)

No pierda más quien ha tanto perdido no.piér.da.más.quie.há.tan.to.per.dí.do

(Soneto VII, 2)

como acontece a quien ha ya escapado co.moa.con.té.cea.quién.ha.yaes.ca.pá.do

(Soneto VII, 7)

me quitó al mundo y m’ha en ti sepultado

me.qui.toal.mún.doy.m’háen.ti.se.pul.tá.do

(Soneto XVI, 13)

del grave mal que en mí está de contino del.grá.ve.mál.queen.míes[miés].ta.de.con.tí.no

(Soneto XX, 11)

Albanio es éste que 'stá 'quí dormido al.bá.nioes.és.te.que's.ta.quí.dor.mí.do

(Égloga II, 98)

Cómo pudiste tan presto olvidarte

có.mo.pu.dís.te.tán.pres.tool.vi.dár.te

(Égloga II, 578)

¡Oh santos dioses!, ¿qué’s esto que veo?

óh.san.tos.dió.ses.qué's.es.to.que.vé.o

(Égloga II, 775)

Camila es ésta que está aquí dormida ca.mí.laes.és.ta.quees.taa.quí.dor.mí.da 
También han sido tildados de duros o forzados algunos endecasílabos de Garcilaso de la Vega en los que una vocal acentuada de la serie cerrada $/ i, u$ / se encuentra en contigüidad con vocal no acentuada de la serie /a,e,o/. El verso más frecuentemente citado es el siguiente:

Hermosas nymphas que en el río metidas (Soneto XI, 1) her.mó.sas.ným.phas.queen.el.río[rió].me.tí.das

La palabra río, considerada gramaticalmente como bisílaba, constituye aquí en realidad una sola sílaba métrica. Habría tenido lugar una «licencia» poética, llamada sinéresis, en virtud de la cual las vocales $i$ y $o$ no formarían ya hiato, sino diptongo. Ahora bien, difícilmente podría admitir la gramática tradicional un diptongo en el que la vocal nuclear fuera la más cerrada -la $i-$, mientras que la vocal más abierta -la $o$ - cumpliera meramente el papel de elemento marginal. Para que exista una sola sílaba, tendría que entrar en juego un mecanismo de dislocación acentual: el acento habría de desplazarse de la vocal más cerrada a la más abierta. En definitiva, en lugar de pronunciarse río, tendría que decirse rió.

Veamos lo que nos dice la Real Academia, en el Esbozo de una nueva gramática de la lengua española (1973), a propósito de un caso similar, esto es, de contacto de una vocal abierta y átona con una vocal cerrada y tónica. En esta ocasión, la unión silábica se da entre palabras contiguas:

Otra curiosa «licencia» poética, que en este caso afecta también a la rima, aparece en el endecasílabo de Garcilaso (Égloga I, v. 122): Y por nuevo camino el agua se iba, donde se computa como una sílaba el grupo vocálico final /éi/, con dislocación del acento, lo que no impide que iba sea consonante de estiva. Lo mismo ocurre en Góngora (Sonetos completos, ed. 1969, pág. 27): Que a Júpiter ministra el garzón de Ida, verso aconsonantado en -ida a pesar de la sinalefa /éi/, o en Ponga, pues, a las querellas que usa (ibíd., 127), con sinalefa /éu/, pero con rima $-u s a^{16}$.

Como es habitual en ciertos estudios gramaticales y académicos, se considera la sinalefa -al igual que la sinéresis- como una ${ }^{16}$ Párrafo 1.6.8.c. 
licencia, que en este caso es aún más «curiosa». Es de advertir que los grupos vocálicos que se aducen -/éi/, /éu/- se computan «como una sílaba». No es que realmente se piense que constituyen una auténtica sílaba, sino que se les concede ese valor sólo en virtud de la referida licencia poética. Por supuesto que se asume que el acento no puede recaer sobre la $i$ o la $u$-/eí/,/eú/-, vocales cerradas, sino sobre la $e$, vocal más abierta, dándose así una «dislocación del acento». Pero, a pesar de todo, se reconoce que existe rima en -iba, -ida y -usa.

Ahora bien, por definición, la rima no es otra cosa sino la completa igualdad de sonidos con que terminan dos o más palabras a partir de la última vocal acentuada. Por lo tanto, y en pura lógica, si existe rima (que sí que existe), el acento ha de recaer, necesariamente, en la $i$ de $i b a$, en la $i$ de Ida y en la $u$ de usa:

$$
\begin{aligned}
& \text { y.por.nué.vo.ca.mí.noel.á.gua.seí.ba } \\
& \text { quea.jú.pi.ter.mi.nís.trael.gar.zon.deí.da } \\
& \text { pón.ga.pues.fín.a.las.que.ré.llas.qeú.sa }
\end{aligned}
$$

Para que exista rima, no puede darse la dislocación del acento. Así pues, habría que revisar algunos criterios tradicionales, y afirmar que, en casos como éstos, no tiene sentido desplazar el acento a la vocal más abierta. Es precisamente la vocal más abierta la que se oscurece y se hace menos perceptible, hasta el punto de asumir el papel de mero elemento marginal. Si no queremos incurrir en la contradicción de admitir simultáneamente la existencia de rima y de dislocación acentual, hemos de rechazar decididamente esta última. Así lo percibían Góngora y Garcilaso. Y así lo percibe el atento lector actual de poesía. De forma análoga, el río donde juguetean las hermosas ninfas de Garcilaso (Soneto XI, 1) puede seguir siendo río, y no rió, como palabra monosilábica:

her.mó.sas.ným.phas.queen.el.río.me.tí.das

Fernando de Herrera escribía rîo, y en otros lugares mîos, perdîa, vîa, queriendo indicar con el acento circunflejo la presencia de un especial fenómeno fonético, que afectaba directamente al grupo vocálico. La vocal resaltada por la tilde era precisamente 
la $i$, la más cerrada, que pasaba a ser así el centro del grupo silábico. Podríamos hablar simplemente de diptongo, o unión de vocales en contacto, frente a hiato, o desunión de las vocales. Pero, como en otro lugar se ha señalado ${ }^{17}$, sería preferible hablar de zeuxis frente a azeuxis.

En efecto, zeuxis es término más exacto que diptongo, ya que su significado no se limita a sólo dos elementos fónicos. Pueden ser tres (el llamado triptongo) o más las vocales que se agrupen en una unidad silábica. Por otra parte, el término diptongo (del

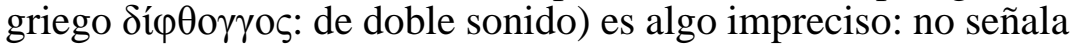
si los dos sonidos o vocales están unidos en una sola sílaba o separados en sílabas diferentes. Del mismo modo, azeuxis carece de las connotaciones peyorativas del hiato (del latín hiatus: hendidura, grieta, abertura, bostezo), que implican una carga afectiva de cacofonía no deseada.

En todos los casos de vocales en contacto, sería más oportuno hablar simplemente de unión o desunión silábica. Y, para ello, la lengua griega nos proporciona dos términos claramente delimi-

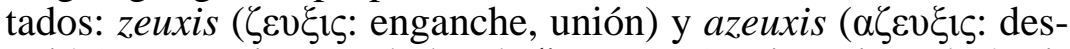

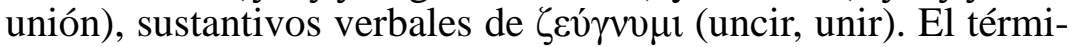
no azeuxis ha venido ya siendo utilizado en la lengua española, justamente como sinónimo de hiato o encuentro de dos vocales que se pronuncian en sílabas diferentes. No ocurre lo mismo con el término zeuxis, como alternativa a la palabra diptongo, pues hasta ahora no ha formado parte de la nomenclatura métrica.

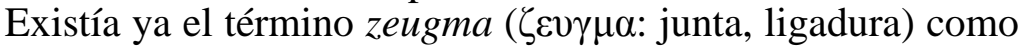
figura retórica de construcción, que también es sustantivo verbal de $\zeta \varepsilon v ́ \gamma v o \mu$ y que consiste en sobrentender una palabra o sintagma en varias oraciones o cláusulas, aunque sólo esté presente en una de ellas. Tanto zeuxis como zeugma son, así pues, sustantivos verbales, si bien el primero expresa la acción del verbo, y el segundo, el resultado. Es lo mismo que ocurre con los términos sintaxis ( $\sigma 0 ́ v \tau \alpha \xi 1 \varsigma:$ orden, disposición, orden de combate) y sin-

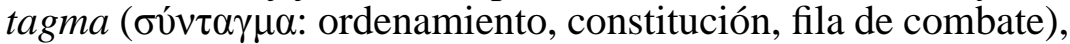
sustantivos verbales que expresan respectivamente la acción y el

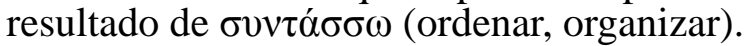

${ }^{17}$ Torre, Esteban: «Zeuxis y azeuxis en la configuración silábica». Rhythmica, Revista española de métrica comparada. 2011, IX, 9, pp. 183-199. 
En los endecasílabos de Garcilaso, es frecuentísima la zeuxis o unión silábica de la vocal cerrada tónica $i$ con las vocales abiertas átonas $a$ y $o$. Se indica con acento circunflejo, de acuerdo con la pauta marcada por Herrera, la situación de la $i$ afectada por la zeuxis:

Yo avîa jurado nunca más meterme a poder mîo y a mi consentimiento por do los mîos, de tal calor movidos Señora mîa, si yo de vos ausente Con más piedad devrîa ser escuchado y más del bien que allí perdîa muriendo ya yo con mi dolor sin guîa camino allá os yrîa a buscar como perdido que nunca dîa ni noche cessan della que de la vîa espantosa atrás me torne serîa de mí, hermosa flor de Gnido fuerça de tu beldad serîa cantada d'aquesto un frîo temor assí a desora el fuego que'l amor tenîa encendido ternîa presente por mejor partido y agradecerîa siempre a la ventura que avîa de ver, con largo apartamiento podrîan tornar d'enfermo y descontento que della un punto no sabîa apartarme que vîa bolar aquella vanda amiga todos venîan al suelo mal su grado seguîase lo que apenas tú barruntas Parecîa que mirando las estrellas rompîa con gritos ella y convocava venîa por nuestra mano, y la cuitada verîa d'aquella que yo tanto amava antes, con mi llorar, hazîa espantados me preguntaban quáles avîan sido de quantas digo quien devrîa escucharme y temerario error que avîa seguido que avîa de ser quien diese la doctrina el qual venîa con Phebo mano a mano vio que'ra el que avîa dado a don Fernando Luego venîa corriendo Marte airado que'l sol embîa delante, resplandece y claro rîo, gozoso de tal gloria en Flandes avîa sido, y el osado y parecîa que'l ocio sin provecho

(Soneto VII, 9) (Soneto VII, 10) (Soneto VIII, 6) (Soneto IX, 1) (Soneto XV, 12) (Soneto XXIX, 7) (Soneto XXXII, 2)

(Canción I, 12)

(Canción III, 13)

(Canción IV, 131)

(Canción V, 12)

(Canción V, 22) (Elegía II, 43) (Elegía II, 66) (Elegía II, 117) (Elegía II, 118) (Égloga I, 285) (Égloga II, 16) (Egloga II, 181) (Égloga II, 250)

(Égloga II, 255)

(Égloga II, 271)

(Égloga II, 272)

(Égloga II, 276) (Égloga II, 294) (Égloga II, 471) (Égloga II, 516) (Égloga II, 522) (Égloga II, 597) (Égloga II, 660) (Egloga II, 1324) (Égloga II, 1329) (Égloga II, 1339) (Égloga II, 1379) (Égloga II, 1393) (Égloga II, 1470) (Égloga II, 1539) (Égloga II, 1596) 


que avîa de ser guïada por su mano
el rîo le daba dello gran noticia
a las que avîa de Tormes aprendido
mas con la lengua muerta y frîa en la boca
que’n delgadeza competîan con ellos
de las colores que antes le avîan dado
mostrava en la labor que avîa texido
pintado el caudaloso rîo se vía
contento con lo mucho que avîa hecho
cuya vida mostrava que avîa sido
de dos pastores que venîan cantando
deste dîa, para mí mayor que un año

que avîa de ser guïada por su mano a las que avîa de Tormes aprendido mas con la lengua muerta y frîa en la boca que'n delgadeza competîan con ellos de las colores que antes le avîan dado mostrava en la labor que avîa texido pintado el caudaloso rîo se vía contento con lo mucho que avîa hecho de dos pastores que venîan cantando deste dîa, para mí mayor que un año
(Égloga II, 1606)

(Égloga II, 1754)

(Égloga II, 1822)

(Egloga III, 11)

(Égloga III, 102)

(Égloga III, 114)

(Égloga III, 146)

(Égloga III, 201)

(Égloga III, 208)

(Égloga III, 227)

(Égloga III, 291)

(Égloga III, 320)

La unión silábica de la zeuxis (tanto en el caso del comúnmente llamado diptongo, como en la sinéresis, la sinalefa o la sinafía) y la separación silábica de la azeuxis (llámesela hiato, diéresis o dialefa) son fenómenos por lo demás habituales, que tienen lugar tanto en la línea sintagmática del verso como en la del lenguaje ordinario, y se realizan no sólo en el interior de la palabra aislada, sino también entre palabras contiguas. En el dominio de la métrica, la poética y la estética, carece de sentido la antigua distinción entre sílabas métricas y gramaticales, o la más reciente entre sílabas fonéticas y fonológicas, tal como se hace en la Nueva gramática de la lengua española (2010):

Las sílabas fonológicas no se corresponden necesariamente con las sílabas fonéticas. En el verso entre el vivir y el soñar (Machado, Nuevas canciones), se observa la diferencia entre estos dos aspectos. Las sílabas fonológicas en.tre.el.vi.vir.y.el.so.ñar se convierten desde el punto de vista fonético en en.trel.vi.vir.yel.so.ñar ${ }^{18}$.

Se nos dice que las sílabas fonológicas «se convierten» en fonéticas, cuando lo que sucede es justamente lo contrario: es la realidad fonética la que se abstrae y se convierte en sistema fonológico. La sílaba presupone el sonido, que es lo que el oído directamente capta. Y conviene poner énfasis en la cualidad acústica, auditiva, del sonido, no en el aspecto meramente oral y articulatorio o en la consideración física de la onda sonora. La sílaba no tiene en sí misma valor fonológico alguno, a no ser como unidad mínima portadora de un acento. Aunque,

${ }^{18}$ Párrafo $1.4 n ̃$. 
a decir verdad, el acento viene a su vez definido, tautológicamente, por un mayor relieve de la sílaba acentuada. La sílaba remite al acento, y el acento a la sílaba.

El análisis de las sílabas y los acentos, que configuran el armazón rítmico del verso, pertenece al dominio de la métrica, la poética y la estética, y no a los estudios gramaticales o lingüísticos. Con buen criterio, la Real Academia Española, que todavía en el Esbozo de 1973 prestaba alguna atención a las sílabas, el acento y la fonología sintáctica, pasa ya por estas cuestiones como sobre ascuas en la Nueva gramática de 2010; y, en el Manual de la Nueva gramática, dedica significativamente a las unidades fónicas sólo dos brevísimos párrafos ${ }^{19}$, que vienen a ocupar no más de media página de un total de novecientas noventa y tres. Por su parte, el tercer volumen de la Nueva gramática de 2011, dedicado específicamente a la fonética y la fonología, considera como «una cuestión controvertida» la agrupación silábica de las vocales en español ${ }^{20}$.

Con criterios métricos, estéticos y poéticos, y atendiendo también a la historia de la lengua, pueden resolverse algunos otros problemas que pueden tal vez surgir en la lectura de los endecasílabos de Garcilaso de la Vega. Veamos algunos ejemplos:

y más me duele el no osar deciros y.más.me.dué.leel.nó.o.sár.de.zí.ros

(Soneto XXXVIII, 3)

Este verso reza así en la edición de Fernando de Herrera:

I mas me duele nunca osar deciros i.más.me.dué.le.nún.cao.sár.de.zí.ros

(Soneto XXXII, 3)

Según Rivers, con esta enmienda o variante Herrera habría evitado «el hiato difícil» ${ }^{21}$ de «no osar». Pero, a decir verdad, no es tan «difícil» este hiato, dialefa o azeuxis. En la conciencia lingüística del hablante español del primer tercio del siglo XVI estaba aún presente el recuerdo del antiguo non, lo cual impedía la sinalefa o zeuxis entre «no» y «osar».

\footnotetext{
${ }^{19}$ Párrafos 1.2.1 y 1.2.2.

${ }^{20}$ Párrafo 8.5a.

${ }^{21}$ Rivers, Elias L.: Obras, cit., p. 162, nota 3.
} 
En el siguiente verso, la forma «sino» (de si y no) que aparece escrita como una sola palabra, no pierde su valor original (si no, si no es, a no ser):

$$
\begin{aligned}
& \text { yo no nascí sino para quereros } \\
& \text { yo.no.nas.císi.nó.pa.ra.que.ré.ros }
\end{aligned}
$$

(Soneto V, 9)

En otros versos, los pronombres «me» $\mathrm{y}$ «los» aparecen como formas tónicas, tal como se dijo a propósito de Égloga I, 128:

dándome a entender que mi flaqueza dan.do.mé.aen.ten.dér.que.mi.fla.qué.za

(Canción I, 49)

que ya no me refrenará el temor que.ya.no.mé.re.fre.na.ráel.te.mór

(Canción II, 24)

juntándolos, con un cordón los ato cor.tán.do.lós.con.ún.cor.dón.los.á.to

(Égloga I, 363)

Como es sabido, la acentuación de la sílaba final de las palabras esdrújulas es habitual en el endecasílabo inglés shakespeareano. Y no es infrecuente en la métrica castellana. Así, en el siguiente verso, ha de leerse lagrimás por lágrimas:

en lágrimas, como el lluvioso viento

en.la.gri.más.co.moel.llu.vió.so.vién.to

(Elegía I, 23)

Los versos que a continuación se relacionan, claramente acentuados en las sílabas $2^{\circ}, 8^{\mathrm{a}}$ y $10^{\mathrm{a}}$, llevan en posición $4^{\mathrm{a}}$ las partículas «que» $\mathrm{y}$ «de» respectivamente. Esta posición, lugar privilegiado de expectativa para la realización del endecasílabo sáfico, confiere a dichas partículas un especial relieve, que enfatiza las expresiones «el fruto que» $\mathrm{y}$ «lo menos de»:

el fruto que con el dolor sembramos el.frú.to.qué.con.el.do.lór.sem.brá.mos

(Égloga II, 9)

lo menos de lo que'n tu ser cupiere lo.mé.nos.dé.lo.que’n.tu.sér.cu.pié.re

(Égloga III, 31)

En situación análoga se encuentra la expresión «do quiera que» en este otro verso: 
do quiera que sauzes de oy más se hallen do.quié.ra.qué.sau.zes.deoy.más.se.hállen

(Égloga III, 359)

Resulta ciertamente difícil prescindir en este caso del acento de la palabra sauzes. Es preferible, sin duda alguna, la variante que nos ofrece Herrera:

do quiera que d'oi mas sauzes se hallen do.quié.ra.que.d'oi.más.sau.zes.se.hállen

Finalmente, hay que advertir que algunos textos de la edición de Rivers exhiben innegables imperfecciones; pero éstas en modo alguno son responsabilidad de Garcilaso de la Vega. Así, por ejemplo, los sonetos XXXIX y XL acumulan tantos defectos que obligan a descartar categóricamente la autoría garcilasiana. Ya el mismo Rivers hizo notar, a propósito de estos sonetos, cómo «Keniston (pp. 216-217), por sus endecasílabos y rimas defectuosas, cree que no pueden ser auténticos y los edita en apéndice ${ }^{22}$. A todo amante de la buena poesía, que leyera inadvertidamente tales sonetos, se le recomienda contrarrestar su comprensible enojo con el recuerdo de algunos de los mejores versos del verdadero Garcilaso:

coged de vuestra alegre primavera

el dulce fruto antes que'l tiempo airado

cubra de nieve la hermosa cumbre

(Soneto XXIII, 9-11)

Corrientes aguas puras, cristalinas,

árboles que os estáys mirando en ellas

(Égloga I, 239-240)

somorgujó de nuevo la cabeça

y al fondo se dexó calar del río

(Égloga III, 83-84)

No, no existen endecasílabos defectuosos, ni anómalos, ni dactílicos, en la poesía de Garcilaso de la Vega. Un exhaustivo análisis de toda su obra así lo pone de manifiesto. Estamos en presencia de un auténtico poeta, un poeta nato, uno de los más altos exponentes -junto a San Juan de la Cruz, Gustavo Adolfo Bécquer o Rosalía de Castro- de la mejor poesía lírica española

$\overline{{ }^{22} I b i d ., ~ p . ~} 164$. 
de todos los tiempos. El eco de los perfectos endecasílabos de Garcilaso llega hasta nuestros días a través de las voces de Juan Ramón Jiménez, Manuel Machado, Antonio Machado, Jorge Luis Borges, Federico García Lorca, Blas de Otero... 